\title{
Physical activity: what is already being done and how we can avert 1 million deaths annually in future
}

\section{Carl Johan Sundberg}

Physical inactivity is a major and increasing contributor to poor health and premature death across the world. People can increase their health-enhancing physical activity (PA) levels through a combination of personal efforts and a supportive and conducive environment. Healthcare has a key role to play, but needs more knowledge, organisation and incentives to fulfil its potential.

Physical inactivity caused over 5.3 million deaths, or $9 \%$ of premature mortality, worldwide in $2008 .^{1}$ If physical inactivity were decreased by $25 \%$, more than 1 million annual deaths could be averted. The health improvement of enhanced PA is largely due to the lower risk of cardiovascular disease, metabolic disease and cancer. Equally importantly, increased PA also improves quality of life and helps to prevent or treat mental health disorders.

\section{MULTIPRONGED APPROACH NEEDED TO INCREASE PA LEVELS-NO MAGIC BULLET}

A decreasing number of people across the world reach the PA levels recommended by the $\mathrm{WHO}^{2}$ (at least 150 min weekly of moderate-intensity or at least $75 \mathrm{~min}$ of vigorous-intensity aerobic PA and musclestrengthening activities on 2 or more days a week).

No single decision-making level or solution will increase population levels of PA. Government policies are fundamental for city planning regulations, for physical education curricula in schools, for setting legal requirements for employers concerning employee health and for establishing national guidelines for PA. At the individual level, healthcare has a central role. Not to be forgotten, each individual has a large responsibility for their own health.

\section{HEALTHCARE AND HEALTH PROFESSIONALS PLAY A KEY ROLE}

In spite of all the shortcomings in the healthcare systems of the world, most people trust their healthcare staff. There is some benefit in even brief counselling about healthy behaviour effect. ${ }^{3}$ However, there are

Correspondence to Dr Carl Johan Sundberg, Department of Physiology and Pharmacology, Karolinska Institutet, Stockholm 17177, Sweden; Carl.J.Sundberg@ki.se several reasons why, for example, PA counselling is employed to a very limited extent.

- First, healthcare staff in general are not confident to address the need for increased PA for patients. Therefore, education and training for all staff is key to increasing knowledge.

- Second, healthcare is reimbursed largely for procedures and visits, not patient outcomes. Therefore, to make individualised lifestyle counselling and follow-up more likely, incentivising mechanisms must be put in place.

- Third, physicians, nurses and physiotherapists have a heavy workload and limited time for each patient. Therefore, to make it easier and more likely that PA is recommended, specific and seamlessly integrated work processes and tools are needed.

\section{PA ON PRESCRIPTION WORKS: TIME FOR ACTION}

PA on prescription (PAP), a method used for decades in some countries, is a feasible way to increase an individual's PA levels. ${ }^{4}$ It is an individualised written prescription for PA for prevention and/or treatment of disease. The prescribed activity can either be performed individually or with local activity organisers, for example, gyms, sports clubs, walking clubs, patient organisations or other associations. A large majority of patients report adhering fully or partially to the prescribed PA. ${ }^{5}$ Even though PA on prescription is used all over Sweden today, the method is still underutilised. It is estimated that approximately 120000 prescriptions were provided in 2014.

\section{STRUCTURED KNOWLEDGE SUPPORT AVAILABLE}

To address the need for evidence-based and structured knowledge support, Swedish Professional Associations in 2001 took the initiative to produce a handbook about PA for the healthcare context. ${ }^{6}$ The 600-page handbook, called FYSS, contains the scientific background for PA recommendations for 40 diseases (eg, cardiovascular, metabolic, orthopaedic, psychiatric, pulmonary, and neurological diseases or cancer) or conditions (eg, pregnancy, old age). The book is now also available in English (free download, http://www.fyss.se/fyss-in-english/),
Norwegian and Vietnamese with more translations planned. ${ }^{7}$

\section{THE NEXT STEP-INTEGRATION WITH ELECTRONIC HEALTH RECORDS}

To make it easier for healthcare professionals to recommend PA and to improve follow-up routines, it is essential to integrate knowledge and decision support tools with the electronic health record systems. Therefore, the upcoming edition of FYSS will work seamlessly with the electronic health record. In a collaborative project between Professional Associations for Physical Activity, the Swedish National Board for Health and Welfare and the Stockholm County Council (the regional healthcare provider), such a pilot system is being designed. At a patient visit, a summary recommendation and possible contraindications pop up when triggered by a specific diagnosis. The physician may then choose to use or modify the recommendation proposed by the system.

Competing interests CJS is Chair, Swedish Professional Associations for Physical Activity, a sub-section in The Swedish Society of Medicine.

Provenance and peer review Not commissioned; internally peer reviewed.
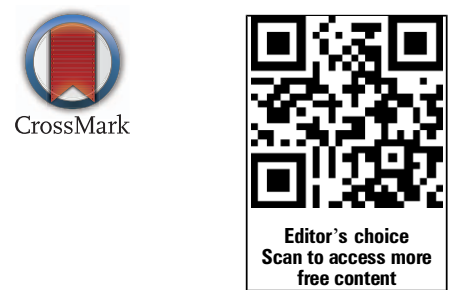

To cite Sundberg CJ. Br J Sports Med 2016;50:319. Accepted 20 January 2016

Br J Sports Med 2016;50:319.

doi:10.1136/bjsports-2016-096026

\section{REFERENCES}

1 Lee IM, Shiroma EJ, Lobelo F, et al. Effect of physical inactivity on major non-communicable diseases worldwide: an analysis of burden of disease and life expectancy. Lancet 2012;380:219-29.

2 Global recommendations on physical activity for health. Geneva: World Health Organization, 2010.

3 Vijay GC, Wilson ECF, Suhrcke M, et al. Are brief interventions to increase physical activity costeffective? A systematic review. Br J Sports Med Published Online First: 5 Oct 2015 doi:10.1136/ bjsports-2015-094655

4 Hellénius M-L. Sundberg CJ. Physical activity as medicine: time to translate evidence into clinical practice (editorial). Br J Sports Med 2011;45;158.

5 Kallings LV, Leijon ME, Kowalski J, et al. Selfreported adherence: a method for evaluating prescribed physical activity in primary health care patients. J Phys Act Health 2009;6:483-92.

6 Swedish National Institute of Public Health. Physical activity in the prevention and treatment of disease. Sweden: Professional Associations for Physical Activity, 2010. http://www.fyss.se

7 Börjesson M, Sundberg CJ. FYSS (physical activity book for prevention and treatment): behavioural change also for the physician? Br J Sports Med 2013;47:937-8. 